\title{
Immune Repertoire Deep Sequencing
}

National Cancer Institute

\section{Source}

National Cancer Institute. Immune Repertoire Deep Sequencing. NCI Thesaurus. Code C158249.

DNA sequencing of the full complement of genes associated with T and B cell antigenspecific receptors in an individual, performed with a high number of replications. 